\title{
An Investigation into Organisation Capacity for National Disaster Management in Zimbabwe: The Case of the Department of Civil Protection
}

\section{Bismark Mutizwa ${ }^{1}$}

${ }^{1}$ Public Administration, University of Zimbabwe. Zimbabwe.

Article History

Received:

20.02.2021

Revised:

04.04.2021

Accepted:

18.04.2021

*Corresponding Author:

Bismark Mutizwa

Email:

bismarkmutizwa@gmail.com

This is an open access article, licensed under: $\mathrm{CC}-\mathrm{BY}-\mathrm{SA}$
Abstract: Across the globe, disasters - both natural and man-made - have threatened humanity. These disasters had grave and devastating impact on human life, infrastructure, and the environment as evidenced by the February 2000 Cyclone Eline and March 2019 Cyclone Idai. This research sought to investigate the Department of Civil Protection`s (DCP) capacity in national disaster management. The research examines how the DCP handled cyclones from 2000-2019 in Chimanimani District. Organisational capacity was assessed on the basis of its core principles which are: leadership, management and operations, community engagement, service and evaluation. The study discovered that inadequate financial and human resources, poor emergency response systems, weak learning and lessons drawing, reactive disaster management, weak pre-disaster management community engagement, poor reconstruction and failure to harmonise military and DCP operational structures are factors undermining DCP's capacity for national disaster management. The research recommends that government should avail adequate resources, DCP should be proactive in disaster management, should openly contract-out reconstruction works, and collaborate with universities to strengthen organisational learning capacity, align military and DCP operational structures and processes and let Non-Governmental Organisations (NGO) distribute food and other humanitarian aid.

Keywords: Cyclone, Department of Civil Protection, Disaster Management, Organisational Capacity. 


\section{Introduction}

The Across the global spectrum, disasters - both natural and man-made - have threatened humanity. The World Risk Report [1] says that global statistics, both from the past and future, show an increase in natural disasters. This is because global annual economic impact allied with disasters were estimated at around US\$ 75.5 billion in the 1960s, US\$ 138.4 billion in the 1970s, US\$ 213.9 billion in the 1980s, US\$ 659.9 billion in the 1990s, US\$ 374 billion in 2011, US\$ 117 billion in 2016 and US\$ 75 billion in 2020 [2]. The calamities that have threatened humanity include floods, earthquakes, tornados, cyclones to mention but a few [1]. These disasters had grave and devastating impact on human life, infrastructure, and the environment [3]. Developed, developing and even resourceconstrained states have set up organisations meant to deal with disasters. To this end, Zimbabwe has the Department of Civil Protection (DCP), nonetheless the organisation has constantly faced criticism over how it manage disasters. This is because there is a discrepancy to organisational objectives and performance. It is against this background that this research intends to interrogate the DCP's organisational capacity for national disaster management using cyclones in the Eastern Highlands particularly cyclone Eline and Idai so as to proffer remedial actions.

In an effort to curb the devastating effects of disasters, Zimbabwe enacted the Civil Protection Act (Chapter 10:06) in 1986 which repealed the Civil Defence Act of 1982 [4], [5]. The legal framework gave room for the establishment of the Department of Civil Protection (DCP) formerly known as Civil Protection Unit (CPU) which seeks to bring normalcy to affected areas and families [4]. The legal instrument defined the operations of the DCP and clearly outlined what is expected of it [4]. The DCP is tasked with the responsibility of establishing emergency plans, post disaster and recovery management plans, the Department is under the Ministry of Local Government [4] [6]. According to the DCP E-Service Charter "the key result area of the Department is Disaster Risk Management (DRM) which entails a spectrum of activities involving prevention/mitigation of disaster risks, preparedness planning, timely early warning and response to rehabilitate affected elements" [6].

The mandate of the DCP is overall mobilisation and coordination of DRM stakeholders from the private and public sectors. The vision of the Department is to promote the, "prevalence of a culture of risk aversion and disaster resilience, strengthened coping capacities and optimal disaster response within the context of sustainable development in all sectors, institutions and at risk communities in Zimbabwe" [6]. Central to the mission of DCP is the coordination and promotion of strategic planning for disasters at the community, local authority and national level in a bid to promote "optimal emergency preparedness and disaster prevention in Zimbabwe" [6].

At its establishment, the Department received warm welcome from the nation at large, which viewed it as a vehicle of bringing back normalcy and comfort in times of disaster thereby restoring hope to the people. However, the organisation in the past has been accused of constantly failing to give hope, comfort and relief to the citizens in times of disasters, this is because of its alleged poor post-disaster management. According to the Department of Civil Protection, Cyclone Eline affected 2.7 million people directly or in directly in the Southern and Eastern part of Zimbabwe, among them were vulnerable groups. The scale or magnitude of the impact has been describe as "huge" with a total cost of US\$ 3,160,799.00 leaving many homeless at the mercy of poverty [7]. The Cyclone Eline floods of February 2000 left approximately over 250, 000 people affected, 90 people dead and the destruction of about US\$ 7.5 million worth of goods [4] [8] [9].

In addition, the World Food Programme Zimbabwe [10], citing Timber Producers Association, noted that 3340 hectares of timber was damaged valued at US\$10 000000 which is one year's produce and this had a devastating impact on the livelihoods of the people. Infrastructure in Mutare and Chipinge was destroyed e.g. granaries, bridges, schools, telecommunications lines, roads clinics. Electricity and telecommunication lines are among other essential facilities that were affected by the cyclone [10] [4]. Estimation rehabilitation costs of irrigation schemes and water resources was US\$ 2 042047 [10]. Approximately over 16000 chickens, 13000 goats, 2000 cattle and 1000 donkeys died due to the cyclone [10].

The DCP was warned of the Cyclone by the Zimbabwe Meteorological Services on the 15th of February 2000 and disseminated the information on newspapers, radio and television two days before the Cyclone. The information lacked vital preparedness and mitigation measures that the recipients could have implemented, and the organisations was also criticized for poor dissemination coverage which gravely affected their disaster mitigation mandate [10]. The other disasters that the organisation also dealt with include Cyclone Japhet in 2003, Cyclone Cela in 2013, Tokwe Mukusi and 
Tsholotsholo floods in 2014, Cyclone Dineo in 2017, Cyclone Idai in 2019 and various serious road accidents to mention but a few [4].

However, common to all is the DCP's alleged inability to robustly handle the aftermaths of the disasters. Approximately 250000 people were affected by the recent Cylone Idai; 120000 children affected, 154 deaths and 189 missing mid-March 2019 [11]. Mavhunga [12] noted that by the end of March 2019, the death toll had reached 181 with more than 40000 in need of food assistance and 7 000 had their houses destroyed. According to UNICEF Zimbabwe Report: 7 [13] "as of 14 April, 334 people had been reported dead and over 257 people were reported missing due to the cyclone", 270,000 people were affected, including 129,600 children.

The DCP has structures at national, provincial and district level but nothing at ward level when the latter is the most affected level as evidenced by Ngangu area in Chimanimani, in the Cyclone Idai. However, after Cyclone Idai, the DCP set district command centre in Chimanimani and Chipinge with Mutare being the subnational and provincial command centre coordinating all efforts aimed at managing the disaster [11]. The silence of DCP in disseminating information prior to Cyclone Idai raises questions about the organisation's capacity in disaster management. It may also show that the organisation learned little in previous cyclones like Cyclone Eline where poor information dissemination and coverage was said to be one of the major factors that led the Cyclone to catch the citizens unprepared [10]. In a bid to revamp the DCP the government made disaster management a vital component of vision 2030, it is also engraved in the Transitional Stabilisation Policy (TSP) [14]. The European Union (EU) is said to have found national disaster management budget wanting and availed $€ 7$ million, since in the 2019 budget the DCP was allocated only \$ 2335000 [15] [16]. It is against this background that the research seeks to investigate organisational capacity for disaster management.

\section{Literature Review and Analytical Framework}

\subsection{Organisational Capacity}

For Cox et al [17] citing Yu-Lee [18], organisational capacity entails an "organisation`s ability to perform work". Eisinger [19] called it the empowering dynamics that enable an organisation to undertake its task and achieve goals and objectives. In the public sector realm, organisational capacity entails government's aptitude, capability to marshal, direct, develop as well as control information, human, physical and financial resources in a manner that advances organisational objectives and goals [20]. In short, it denotes the organisation's shrewdness in directing and monitoring resources in a swift manner that allows it to deal with challenges in a timely and effective way [21], [22]. It is imperative to note that organisational capacity varies across organisations and sectors, as various sectors are driven by a myriad of differing arrays of incentives, while private entities aim to increase profits, public entities prioritise efficiency in public service delivery [23] [24].

Conceptualisation of capacity even in one sector differs depending on the vision, size, mandate and department. Nonetheless, organisational capacity can be measured in terms of human capital, skills, resources, adaptive and administrative capabilities [23] [25] [26] [27]. Morgan [28] propounded that capacity is established by five vital capabilities which to a lesser and greater extent are visible in all organisations. The five capabilities are: capability to integrate, adapt, relate, act and generate development results. The capabilities are sustained by the following pillars of organisational capacity which includes leadership capacity, management and operations capacity, community engagement capacity, service capacity and evaluation capacity.

\subsection{Disaster Management}

Disaster management denotes the art and science of managing resources, structures and responsibilities aimed at addressing all forms of catastrophes [29]. It is also known as emergency management [30]. Kawara [31] noted that disaster management embodies response, recovery, rehabilitation and mitigation, all aimed at minimizing disaster aftermaths. The World Risk Report [1] reinforces the above view by pointing out that central to disaster management are policies, administrative and operative decisions and actions aimed at curbing and reducing the impact of catastrophes. It is infused with human rights values and humanitarian principles that seek to honour human dignity and restore normalcy in affected areas [32].

The management of disaster is a mammoth task, as such it requires a comprehensive management cycle that includes the shaping and development of public policies as well as plans that lessen disaster effects on infrastructure, people and property. Disaster management follows a six-stage cycle which 
embodies disaster impact, response, recovery, development, mitigation and preparedness [4] [33] [34] [35]. For Carter [36] disaster management cycle includes disaster impact, response, rehabilitation, reconstruction, development, prevention, mitigation and preparedness. The disaster management cycle varies in terms of terminology in its structures and stages but common to all is the continuum element meant to minimise disaster effect. All disaster management cycles have two distinct phases which are crisis management and risk management or capacity building [37] [38]. This can be evidenced by Figure 1.

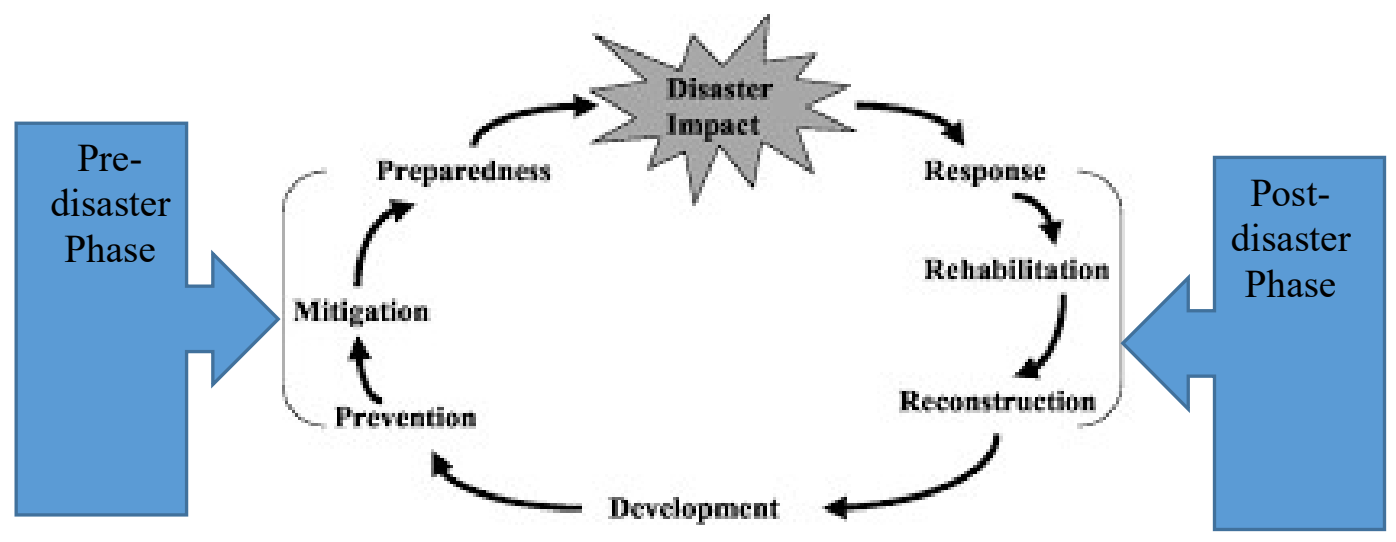

Pre-disaster Phase

Post-disaster Phase

Figure 1. The Disaster Management Cycle [36]

\subsection{Case Studies}

\subsubsection{The Federal Emergency Management Agency (FEMA) in the USA}

President Carter on the 1st of April 1979 established the FEMA [39] [40] [41]. The FEMA was tasked to deal with Federal disaster and provide guidance, comfort and normalcy in times of crises [39]. FEMA has successfully fulfilled this task though it is not immune to challenges. The FEMA has played a crucial role in some of the most devastating crises, for example, the 1993 Great Midwest Floods, the 1994 Northridge Earthquake, the Alfred Murrah building terrorist attack of 1995, the 2001 September terrorist attack on the Pentagon and the World Trade Centre (WTC), 2005 Hurricane Katrina, the 2018 Maryland flooding and Hurricane Florence as well as the 2019 Midwestern and Mississippi river floods [39] [42]. The FEMA has made use of the National Preparedness System (NPS) to promote robust disaster management [43]. At the core of NPS is the Threat and Hazard Identification and Risk Assessment (THIRA) which helps the organisation build its preparedness capacity by systematically examining possible emergencies thereby revamping its mitigation measures [43].

\subsubsection{The Central Disaster Management Council (CDMC) in Japan}

Des Marais et al [44] propounded that "Japan is an epicentre for natural disasters" because, the country is situated on numerous dynamic "faults, having multiple active volcanoes, experiencing typhoons every summer". The nation of Japan is subjected to hurricanes and floods and as such, it is a nation that cannot survive without a viable disaster management [44] [45]. In the 1940s and 1950s, Japan was constantly ravaged by earthquakes, tornados, hurricanes, and typhoons to mention but a few. The 1959 Isewan typhoon had grave devastating effects, thus in an effort to curb such effects the Disaster Countermeasures Basic Act was enacted in 1961 [44] [45] [46]. The enactment of the Disaster Countermeasures Basic Act paved way for the establishment of the CDMC [44]. The CDMC was given a mammoth task of disaster management and capacity building, ensuring national disaster preparedness and possible comprehensive countermeasures [47]. The CDMC has been glorified for its role in disaster management as well as its ability to examine its performance and learn from its mistakes. A good example is a series of performance reviews after the 2011 Great East Earthquake which was considered to be the most devastating in the modern history of Japan [45]. Therefore, the 
CDMC has a viable evaluation, learning and adaptive capacity which are key fundamental pillars of organisational capacity for national disaster management.

\section{Methodology}

The research used the qualitative paradigm to investigate organisational capacity for national disaster management. The qualitative paradigm allowed the inquiry to ask questions the following questions: What is organisational capacity for national disaster management? What is the legal framework governing the operation of Zimbabwe's DCP? What are the strengths and shortcomings that the DCP is encountering in national disaster management? What remedial actions can be adopted to increase organisational capacity in managing national disasters? The study focused primarily on cyclones in Eastern Zimbabwe from 2000. It benefited from purposive and convenience sampling. Documentary review, key informant interviews and observations were used to gather data. The research made use of content analysis. Ethical considerations such as participants' right to privacy, confidentiality, anonymity and informed consent were upheld.

\subsection{Findings and Discussion}

\subsubsection{The DCP's Capacity for National Disaster Management}

4.1.1.1. Leadership Capacity

The study discovered that the DCP has a viable strategic apex that comprises members from various government departments and private entities who bring in different expertise. The National Civil Protection Committee (NCPC), which is chaired by the Director in terms of section 4 (2) (a) of the Civil Protection Act (Chapter 10:06), which is the strategic apex responsible for deliberating on matters affecting the Department and how it can overcome those challenges. According to the Chairman of DCP Chipinge, who demonstrated knowledge and experience about NCPC's functions, "the NCPC has the power to draft long-term and short-term goals for the Department". The Chairman of DCP Chipinge noted that the strategic apex is complemented by the organisational structure. The organisation adopted the machine bureaucracy structure with a "clearly defined hierarchy, formalisation in many procedures, standardisation and a centralised decision-making system". He said the machine bureaucracy structure enables the operations of the DCP which are "interdisciplinary and multi-sectoral in scope and promote formal planning and systematic audits for organisational optimal efficiency in national disaster management".

However, the Head of the DCP Chipinge Shelter Cluster and Head of DCP Chimanimani Social Welfare Cluster noted that the DCP's leadership capacity has remained questionable as it has been found wanting many times and recently in the Cyclone Idai. They posed rhetorical questions in their narrative, "How can we say the organisation has a viable leadership capacity when some of the soldiers deployed to help during Cyclone Idai refused to report to the District Development Coordinator (DDC) who is the DCP chairman saying we report to our superiors in the military?". Therefore, this had a negative impact on the coordination of emergence rescue mission as the lines of command at times where not harmonised. Nonetheless, the research noted that this problem is inherent in the DCP every time the military is deployed to assist. According to the Head of DCP Chipinge Shelter Cluster and Head of DCP Chimanimani Social Welfare Cluster "the genes of this problem can be traced back to Cyclone Eline of 2000, Cyclone of Japhet 2003 up to every national disaster that military personnel were deployed to assist". Another rhetoric question which was asked is "where is leadership capacity when the organisation struggles to adapt and coordinate effectively its operations and human resources?" The study discovered that DCP's struggle to "adapt and coordinate effectively its operations and human resources" was due to organisational inability to synthesise military and DCP personnel, owing to the military organisational protocol and pride.

\subsubsection{Management and Operations Capacity}

Management and operations capacity are closely related to leadership capacity. The former is more concerned about the organisation's ability to recruit, develop and retain talent while the latter focuses on directing and controlling the organisation through crafting sound and unambiguous policies. Prentice and Brudney [23] stated that management and operations capacity primarily focus on "internal-facing capacities" which encompass the ability of a corporate to recruit, develop and retain talent, manage its finances as well as maintenance of vital infrastructure and systems. According to the Head of the DCP Chipinge Health Cluster, "during and after Cyclone Idai DCP Chimanimani for a month had no management and operational capacity". This is because the entire DCP Chimanimani 
administration and its four cluster committees which include Shelter, Water Sanitation and Roads, Relief and Psychological Services and Social Welfare "were locked down by the Cyclone". This means they had little service to offer as it was the most affected district with most of its resources destroyed by the Cyclone. The magnitude of the cyclone was unbearable as most bridges and roads were damaged, for example, "Risutu Valley (Kopa) was totally inaccessible for DCP Chimanimani team to conduct emergence rescue missions". This gave "Chipinge DCP operational management of both districts for some time". The Head of DCP Chipinge Health Cluster stated that, the DCP team from Chipinge became the "focal personnel in the coordination of rescue missions" which include temporary evacuation, immediate recovery and reconstruction, provision of all emergency services such as shelter, health, food, relief and psychological services with with "Makandi Estate in Chpinge providing airstrip and refuelling facilities for swift emergence management".

According to the Head of DCP Chipinge, the Shelter team managed to build more than 700 tents for emergence evacuation. The Head of DCP Chimanimani Shelter Cluster stated that, "though some of our areas were inaccessible our colleagues from DCP Chipinge did a marvellous job in evacuating the survivors and offering them temporary shelter in Risutu valley Kopa". The Head of DCP Chimanimani Shelter Cluster noted that, "while we could not do much at the moment of the Cyclone as most of our resources were badly affected, we managed to put two hundred families into safety with the help of the Chimanimani Hotel management which opened their hotel for use". However, the Head of DCP Chimanimani Shelter Cluster argued that, "our efforts could not go beyond expected as we had some difficulties in man power and resources". The challenges emanate from the fact that the Department has no "functional management operations capacity as it does not directly recruit, develop and retain talent at provincial and district level".

In addition, on the 7th of October 2019 the Head of the DCP Chipinge Relief and Psychological Service Cluster referred to loss of institutional memory due to personnel changes in the Department. "For example, the people that oversaw Cyclone Eline disaster of 2000 are not the same people overseeing Cyclone Idai". The whole "DCPC has new people" and this has a negative impact on operational management and institutional memory as "there is no talent which has been retained". The Department's failure to recruit, develop and retain talent has gravely affected organisational prevention, mitigation and preparedness capacity for national disaster management. The Head of the DCP Chipinge Relief and Psychological Service Cluster noted that, "in as much as the District Subcommittee meets every month and as long as talent is not developed and retained the Department will always been incapacitated in times of national disaster management".

Management and operations capacity are not only limited to recruiting, developing and retaining of talent. They cover the organisation`s ability to manage its finances as well as maintenance of vital infrastructure and systems. According to the Head of Chimanimani DCP Health Cluster, "the Department still has a long way to go in this area". He noted that the management and operations capacity of DCP are being "affected by inadequate funds". According to the Head of Chimanimani DCP Health Cluster, the Department has not received adequate funds from the state. Last year in November the Department had already exhausted its $\$ 3000000$ budget allocation in dealing with a wave of fire that destroy property around the country and the cholera outbreak that left forty-seven dead. Therefore, instead of raising DCP`s budget allocation, the government allocated only $\$ 2335$ 000 to the Department in the 2019 budget despite its $\$ 10000000$ budgetary bid [15]. The budgetary allocation testifies to the government's attitude towards national disaster management as the Department was given less than a quarter of what it had requested. This is an inherent problem, every year the Department faces budget constraints, despite the fact that the government made disaster management a vital component of vision 2030 [14].

In addition, the study noted that in Chipinge and Chimanimani, DCP has no infrastructure and systems to maintain and use in times of disaster management which is specifically designated for the Department. The organisation relies on vehicles that it borrows from other government departments. However, at times the vehicles will be engaged in other activities. According to the Head of DCP Chimanimani Social Welfare Cluster, the Cyclone started "on Thursday 14 March 2019. Due to the fact that we do not have our own resources and cars we could not begin rescue operations until Monday 18 March 2019". The Head of DCP Chipinge Shelter Cluster noted that, "on Friday 15 March 2019, we only had an emergency meeting but no rescue operation was sanctioned as there were no adequate resources to do impact assessment". This demonstrates organisational resource constraints in national disaster management. This narrative resonates with Risutu Valley (Kopa) 
ZAOGA Pastor and Ngangu Primary School teacher who stated that, for four days, they felt as if the world has abandoned them as they were surrounded by floods with no communication to the world.

\subsubsection{Community Engagement Capacity}

Community engagement capacity is a vital component of national disaster management. It primarily focuses on how the organisation interacts with community partners, media, sponsors and other corporates in a bid to create a conducive environment to fulfil its goals and objectives [23]. The establishment of a robust community engagement is built upon four fundamental pillars which are: communication and advocacy, community partnerships, fund development and volunteer management [17], [27], [48]. In national disaster management community engagement is on two dimensions. The first dimension being pre-disaster management and the second dimension being post-disaster management. The community engagement capacity of the DCP in post-disaster management has been described as "great" while that of pre-disaster management was found to be "disastrous" by the Head of DCP Chimanimani Social Welfare Cluster. This is because the Department is in constant communication with survivors of Cyclone Idai.

The Chimanimani Relief and Psychological team together with the Social Welfare team meet after every two weeks with survivors in Risutu (Kopa) and Ngangu, conducting various rehabilitation educational programs on how residents can overcome depression and nightmares that were brought by the grave impact of the Cyclone. According to the Heads of DCP Chimanimani Health team and Social Welfare team, "despite resource constraints we have continued offering our support to the residents". Plan International, International Rescue Committee (IRC), Goal, Christian Care and World Vision have also played a significant role in offering the same services to the residents. The ability of the DCP to interact and partner with various organisations in times of disaster and after clearly demonstrate the organisation's understanding of the fundamental pillars of community engagement capacity. The research noted that DCP has many weaknesses but post-disaster management community engagement has been done in "an acceptable manner that has facilitated a robust rehabilitation process" said a male Ngangu Primary School Teacher at Ngangu Township.

The Shelter team from DCP Chimanimani has also played a significant role, in educating the residents of Ngangu and Risutu (Kopa) on how to build houses and identify areas which are likely to be affected by floods in the rainy season. The DCP conducted the meetings in partnership with various Nongovernmental Organisations (NGOs) which include Japan International Cooperation Agency (JAIC), International Organisation for Migration (IOM), Care International, Africa Ahead and Red Cross. The inclusion of NGOs shows a robust community engagement capacity which promotes intra- and inter-sectoral collaboration that is determined to ensure an optimum national disaster management.

\subsubsection{Service Capacity}

Service capacity refers to the corporate's ability to design viable programs that respond to the needs of the customers, monitor and promote quality implementation as well as recalibrate the corporate's activities to meet demand trends [23]. Regarding the DCP, service capacity means the department's ability to design, implement and recalibrate pre-disaster and post-disaster management measures in a bid to curtail disaster. According one Africa Ahead Field Officer, the DCP's service capacity "is weak if it has any". The Field Officer noted that "there is a difference in having organisational management and service capacity; there can be an organisation but what good is it if it cannot fulfil its task". The Field Officer expressed displeasure by arguing that DCP has become a "corporate dinosaur" which has neither coping nor adaptive capacity.

According to an International Rescue Committee Research Officer, the DCP has good policies but lacks implementation capacity. The Head of DCP Chimanimani Health Cluster and DCP Chipinge Shelter Cluster reinforced the view of an International Rescue Committee Research Officer by stating that "Cyclone Idai came as a surprise and members of the District Committee met on the 11th, 14th and 15th of March 2019 by then it was too late to start initiating sound prevention, mitigation and preparedness implementation measures". The DCP only issued warnings via mobile services. However, one of the major weakness of issuing warnings via mobile phone is that, there is an ongoing constant electricity interruption in the country thus many mobile phones might be off. Equally important to note is the fact there are some who might not be able to read. International Strategy for Disaster Reduction (ISDR) [49], Mhlanga et al [50], Kawara [31] and Mavhura [4] noted that disaster preparedness is capacity building, it entails predetermined measures and activities that are put in place 
to ensure optimum response. Disaster preparedness encompasses the issuance of early warnings, provisional and impermanent removal of property and people from an area that is exposed to threats. In line with this view and the narratives by the Heads of DCP Chimanimani Health Cluster and DCP Chipinge Shelter Cluster, the DCP only managed to issue warnings but did not provide impermanent removal of property and people from areas that were under threat. According to the Head of DCP Chimanimani Shelter Cluster, "we did not even do risk mapping and zoning, which allows the organisation to do pre-impact assessments due to resource constraints". A sign of poor service capacity being initiated by the unavailability of resources, had it done maybe it could have reduced the scale and magnitude of effects caused by Cyclone Idai.

Moreover, emergence response was also poor, noted one male ZAOGA Deacon from Risutu Valley (Kopa). It took four to five days for survivors to get help. However, according to the Chairman of DCP Chipinge which was in charge of emergency rescue missions in Risutu Valley (Kopa), "this was because of poor visibility due to bad weather, telecommunication and electrical lines had been affected, lack of vehicles (in-road and off-road) and resources that are specifically stationed for DCP activities". Apart from vehicles the organisation did not have fuel for the vehicles they later mobilised from other government departments. All the DCP members Chipinge and Chimanimani except for two that the research failed to conduct interviews with, acknowledged their poor response but blamed it on lack of resources. According to the Chairman of DCP Chipinge, "with the little resources we had, we tried our best". Forty doctors from various organisations such as the Zimbabwe National Army (ZNA), Zimbabwe Republic Police (ZRP), Zimbabwe Medical Association (ZMA) and Premier Medical Services Investments (PMSI) were deployed to Skyline in Chimanimani, Chipinge Hospital and some in the field. However, measuring their best with the impact of Cyclone Idai, it can be said DCP is incapacitated and their service capacity need to be revamped for sound national disaster management.

The research noted that in the most affected area, Risutu Valley (Kopa), there are some reconstruction activities underway. The ZNA and the South African National Defence Force (SANDF) have provided human and technological capital to speed up the reconstruction process. The study noted that on the 9th of October 2019, one bridge in Kopa just across the ZAOGA church was completed waiting for the official opening while the one which crosses Nyahonde River heading to Kurwaisimba was still under construction. Schools and a clinic have been reconstructed and normalcy in their operations was the order of the day. According to the female ZAOGA Pastor the reconstruction of schools and a clinic took four months, while the bridge took six months. Nonetheless, reconstruction process seemed to be focusing on bridges and schools which is quite reasonable but little has been done to the survivors who are still living in tents. It is now nine months after the Cyclone and no permanent structure has been built for those living in tents, said one Assistant Field Officer from Plan International in Risutu Valley (Kopa). However, on the 25th of October Newsday carried an article which reinforced the findings of the research, noting that approximately "30 0000" people are still living in tents and might just be affected by the rains [51].

\subsubsection{Evaluation Capacity}

Evaluation capacity forms the basis of viable national disaster management. It is through evaluation capacity that DCP can examine the department's past performance in national disaster management and recalibrate its ongoing activities to create resilient system that has sound preventive, mitigation, preparedness, recovery, reconstruct and rehabilitation capacity. The study noted that the DCP has weak evaluation capacity. According to the Head of DCP Chimanimani Health Cluster, "we have no learning capacity. We have failed to learn from previous national disasters and cyclones that have affected Chimanimani District". "The patterns of its poor national disaster management are visible everywhere; they have become a public secret", said one female Ngangu Primary School Teacher at Ngangu Township. The female teacher noted that DCP dealt with Cyclone Eline in 2000, Cyclone Japhet in 2003, Cyclone Cela in 2013, Tokwe Mukosi and Tsholotsholo floods in 2014 and Cyclone Dineo in 2017. Nonetheless, the organisation learned little in all those disasters, consequently leading to service, leadership, management and operations incapacitation during Cyclone Idai.

Gee and Ramuscak [52] stated that with evaluation inquiry and effective use of evaluative outcomes, an organisation establishes robust evaluation capacity which creates room for adaptive capacity. Evaluation capacity focuses on the organisations ability to gather data, determine the impact and examine the lessons learned to revamp the corporates performance [23]. Therefore, according to the Emergence Management Coordinator from Goal, the DCP`s weak evaluation capacity denies the 
organisation the ability to learn from its mistakes, overcome challenges and strengthen its activities towards national disaster management.

The Chairman of DCP Chipinge noted that, in as much as the survivors of Cyclone Idai and the nation at large say:

"We have weak institutional memory and learning capacity, it would be fair if they consider that we are operating with inadequate resources. For example, in our budgetary bid for the year 2019 we requested $\$ 10000000$ but only received \$2 335000 which is less than a quarter of our budgetary bid". "This speaks volume to why we fail to conduct some of the scheduled or pre-planned post disaster management evaluations".

The use of the words "scheduled or pre-planned post disaster management evaluations" testifies to the planned post-disaster management evaluations which are interrupted by the unavailability of resources.

\subsubsection{Survivors' Views on DCP's Capacity}

All the interviewed survivors questioned the DCP's capacity in national disaster management, common to the narratives of the survivors is DCP`s delay in emergence rescue missions which only came after seven days. The survivors also lamented how slow the reconstruction processes is, citing that they are still living in tents. According to a male Ngangu Primary School Teacher at some time, help was not being given to them fairly as partisan politics took centre stage in the distribution of food and clothes. Mafirakureva [53] reinforce the above view by questioning in what capacity was Zimbabwe African National Union- Patriotic Front (ZANU PF) members distributing food aid. For a Ngangu Shop owner, ZAOGA Deacon, "Mushikashika" (taxi) driver this brings into dispute DCP`s capacity in national disaster management as the presence of ZANU PF members in the distribution of food aid was meant to instil fear and force those who belong to other parties to join them. All these narratives by survivors made the research to question DCP's capacity. Although, the research did not find any direct link between DCP and partisan distribution of food, it's failure to reprimand the present of political regalia in the distribution of food donations made, it's independence and apolitical capacity to be questioned.

\section{Conclusion}

National disaster management in Zimbabwe has been gravely compromised by the DCP's organisational capacity which has been found wanting every now and then. This is because there appears to be a discrepancy between the DCP's performance and its mandate, which has consequentially made the organisation less effective. The organisational capacity of the DCP is compromised by a plethora of multifaceted and complementing dynamics as presented above. However, there is still room to reinvigorate DCP, this can be done by considering the following remedial actions.

Few recommendations:

1. Government Should Avail Adequate Resources

The Government should avail sufficient financial resources to capacitate the DCP in its activities. The availability of adequate financial resources will smoothen the operations of DCP. There is need to purchase at least two earthmoving machines; a Grader and Front Loader, five off-road vehicles for each DCP office, from national, provisional and district. This will enable the organisation to implement swift coordination and response of rescue missions.

2. There is need for DCP to recruit adequate workforce

The research recommends the DCP to recruit more personnel, at least four to five individuals who are specially deployed to deal with disaster management at provincial and district levels and operate fulltime in the DCP office. These individuals will then become focal personnel in times of disaster management and it will lead to the creation of organisational specialisation capacity. Thus, skills and experience will be preserved for the betterment of the organisation and nation at large.

3. Let Non-Governmental Organisations Distribute Food Aid

The DCP should let NGOs distribute food and other humanitarian aid. NGOs have the resources and capacity to distribute food aid to survivors in times of disasters. It is imperative to note that they should not distribute food aid on partisan grounds and wearing political 
regalia. Equally important is the need of the DCP to put in place preventive measures against partisan distribution of aid.

4. DCP Should Be Proactive in its Disaster Management

The DCP should utilise pre-disaster management processes to establish organisational capacity. Risk-zoning, pre-disaster impact assessment followed by temporary removal of people and property, should form the basis of proactive disaster management. The warning messages that it sent via various mobile operators should also give more information to the citizens on what they should do, who to call and where to go in times of disasters.

5. DCP Should Contract-Out Reconstruction Works

The DCP should engage other private stakeholders who have a reputable capacity in building resilient structures. Contracting out will bring the much-needed engineering expertise just like what the DCP did with bridges which were joint venture between the South African National Defence Force (SANDF) and Zimbabwe National Army (ZNA) were done.

6. Collaborate with Universities to Strengthen Organisational Learning Capacity

The DCP should collaborate with Universities and encourage students both undergraduate and postgraduates to undertake research that deals with its operations. This is the easiest and cheapest way of conducting systematic evaluations and strengthening learning and coping capacity. In return the DCP should offer book prize awards to the best thesis so as to keep the morale and motivation among students. This was successfully done in Japan, Australia and Canada.

7. Align Military and DCP Operational Structures and Processes

The research proposes that, the Government should ensure that the DCP's strategic apex the National Civil Protection Committee (NCPC) harmonise with military commanders on how best they can align DCP's operational structures in times of disasters. This is to promote swift coordination of emergency rescue missions. It will also enhance DCP's adaptive and coping capacity during emergence rescue missions thereby reducing fatality rate.

\section{References}

[1] World Risk Report, "Focus: The city as risk area," 2014. [Online]. Available http://weltrisi kobericht.de/wp- content/uploads/2016/08/WorldRiskReport_2014.pdf. [Accessed: 2014]

[2] www.statista.com/statistics/61256/natural-disaster-losses-cost-worldwide-by-type-of-loss/

[3] World Bank and International Monetary Fund, Global Monitoring Report: Rural-Urban Dynamics and the Millennium Development Goals. Washington, DC, 2013.

[4] E. Mavhura, "Disaster Legislation: A Critical Review of the Civil Protection Act of Zimbabwe" Natural Hazards, vol. 80, no. 1, pp. 606-621, 2016.

[5] www.drmzim.org/about/

[6] G. L. Chikoto, "Zimbabwe's Emergency Management Systems, and Disaster Management Class Project" Atlanta: Georgia State University, 2004.

[7] https://www.preventionweb.net/files/1318_ZimbabweHFAprogressreport[1].pdf

[8] Government of Zimbabwe, "Zimbabwe National Contingency Plan". Zimbabwe, 2012.

[9] O. Shumba, "Capacity Needs Assessment for Disaster Risk Management in SADC Region: Republic of Zimbabwe Country Report Harare" Government of Zimbabwe and UNDP, 2005.

[10] "World Food Programme Zimbabwe. Assessment of the Impact of Cyclone Eline (February 2000) on the Food" Agriculture and Natural Resource Sector in Zimbabwe, [Online] Available: http://fews.net/sites/default/files/documents/reports/1000050.pdf, [Accessed: 2000].

[11] UNICEF Zimbabwe Report: "Zimbabwe Humanitarian Situation Report. [Online] Available: https://reliefweb.int/sites/reliefweb.int/files/resources/UNICEF\%20Zimbabwe\%20Humanitaria n\%20Situation\%20Report\%20\%28Cyclone\%20Idai\%29\%20\%2024\%20March\%202019.pdf. [Acessed: 2019].

[12] C. Mavhunga, Official Death Toll From Cyclone Idai in Zimbabwe Tops 180. https://www. voanews.com/africa/official-death-toll-cyclone-idai-zimbabwe -tops-180 [Acessed: 2019].

[13] UNICEF Zimbabwe Report: "Zimbabwe Humanitarian Situation Report", [Online] Available: https://reliefweb.int/sites/reliefweb.int/files/resources/UNICEF\%20Zimbabwe\%20Cyclone\%20 Idai\%20Humanitarian\%20Situation\%20Report\%20\%234.pdf. [Acessed: 7, 2019].

[14] R. Zinyuke, "Disaster management key part of Vision 2030: Moyo". The Herald, 4 July 2019.

[15] N. Ndlovu, "EU provides €7 million for disaster management". The Newsday, 5 July 2019. 
[16] "European Civil Protection and Humanitarian Aid Operations". EU provides $€ 7$ million for disaster preparedness in Southern Africa and Indian Ocean region, [Online] Available: $\mathrm{https}$ ://ec.europa.eu/echo/news/eu-provides-7-million-disaster-preparedness-southern-africaand-indian-ocean-region_en [Accessed: 2019].

[17] K. Cox, S. Jolly, S. Van Der Staaij and C. Van Stolck, "Understanding the Drivers of Organisational Capacity", Cambridge: RAND and Saatchi Institute, 2018.

[18] T. R. Yu-Lee, "Essentials of capacity management”. New York: John Wiley and Sons, 2002.

[19] P. Eisinger, "Organizational capacity and organizational effectiveness among street-level food assistance programs", Nonprofit and Voluntary Sector Quarterly, vol. 31, no. 1, pp.115-30, 2002.

[20] S. Barakat, and M. Chard, "Theories, rhetoric and practice: Recovering the capacities of wartorn societies". Third World Quarterly, vol. 23, no. 5, pp. 817-835, 2002.

[21] G. Teskey, S. Schnell, and A. Poole, "Getting beyond Capacity - Addressing Authority and Legitimacy in Fragile States. Paper presented at IRSPM 16th annual conference, Rome, 2012.

[22] S. Waheed, "Capacity Building in Public Sector Organisations", the Pakistan Development Review, vol. 38, no. 4, pp. 913-934, 1999.

[23] C. R. Prentice, and J. L. Brudney, "Are you being served? Toward a typology of nonprofit infrastructure organizations and a framework for their assessment". Journal of Public and Nonprofit Affairs, vol. 4, no. 1, pp. 41-58, 2018.

[24] M. R. Despard, "Can nonprofit capacity be measured?" Nonprofit and Voluntary Sector Quarterly, vol. 46 no. 3 pp. 607-626, 2017.

[25] A. Pazirandeh, "Local Capacity Building: A Logistics Perspective in Disaster Relief. The21th Annual Conference of the Production and Operations Management Society (POMS). Vancouver", 2010.

[26] S. Schnell, "Fragility and State-Building in Fragile and Conflict States. Review of Bank Country Strategies". Washington DC: The World Bank, 2010.

[27] GEO. "Strengthening Nonprofit Capacity: Core Concepts in Capacity Building". Washington, DC: Author, 2016.

[28] P. Morgan, "The Concept of Capacity, the study of Capacity, Change and Performance" European Centre for Development Policy Management, [Online] Available: www.ecdpm.org/Web_ECDPM/Web/Content/Download.nsf, 2006.

[29] A. Khorram-Manesh, "Handbook oF Disaster and Emergency Management", Gothenburg: Kompendiet, 2017.

[30] R. Shaw, and K. Shiwaku, "Future perspective of school disaster education in Nepal", Disaster Prevention and Management, vol. 16, no. 4, pp. 576-587, 2007.

[31] M. T. Kawara, "Disaster management and preparedness as a way of fostering sustainable livelihoods in Zimbabwe": A Case of Mutoko District (2009-2016). B.S.c Thesis. Midlands State University, 2017.

[32] P. De Stefani, "Using social media in natural disaster management: a human-rights based approach" Peace Human Rights Governance, vol. 1, no. 2, pp. 1952017.

[33] Capacity Assessment of the Disaster Risk Management System In Zimbabwe Report. [Online] Available : https://www.cadri.net/sites/default/files/Zimbabwe-Report-May-2017.pdf. [Accessed : 2017].

[34] M. Nojavan, E. Salehi, and B. Omidvar, "Conceptual change of disaster management models: A thematic analysis'Jàmbá": Journal of Disaster Risk Studies, vol. 10, no. 1, pp. 1-11, 2018.

[35] W. N. Carter, "Disaster management: A disaster manager's handbook" Mandaluyong City, Phil.: Asian Development Bank, 2008.

[36] W. N. Carter, "Disaster management - A disaster manager's handbook" Mandaluyong City, Phil.: Asian Development Bank, 1992.

[37] D. Alexander, "Principles of Emergency Planning and Management" Harpenden: Terra Publishing, 2002.

[38] J. Twigg, "Good Practice Review 9. Disaster Risk Reduction”. London: Oversee Development Institute, 2015.

[39] FEMA. The Federal Emergency Management Agency Publication 1. [Online] Available: https://www.fema.gov/media-library-data/20130726-1823-25045-8164/pub_1_final.pdf.

[Accessed: 2010]. 
[40] G. L. Wamsley, and A. Schroeder, "Escalating in a quagmire: The changing dynamics of the emergency management policy subsystem", Public Administration Review vol. 56, no. 3, pp. 235-244, [Accessed: 1996].

[41] NAPA. "Coping with Catastrophe: Building an Emergency Management System to Meet People's Needs in Natural and Manmade Disasters" Washington, D.C.: National Academy of Public Administration, 1993.

[42] GAO. "Emergency Management: FEMA Has Made Progress, Challenges and Future Risks Highlights Imperative For Further Improvements. [Online]. Available: https://www.gao.gov/ assets/700/699640.pdf. [Accessed: 2019].

[43] Annual Performance Report, "Fiscal Years", [Online]. Available: https://www.dhs.gov/ sites/default/files/publications/DHS\%20FY\%202017-2019\%20APR_0.pdf. [Accessed: 2018].

[44] E. A. Des Marais, S. Bhadra, and A. R. Dyer, "In the Wake of Japan`s Triple Disaster: Rebuilding Capacity through International Collaboration" Journal of Advances in Social Work, vol. 13, no. 2, pp. 340-357, 2012.

[45] COJ. "White Paper on Disaster Managemen", [Online]. Available: http://www.bousai. go.jp/kaigirep/hakusho/pdf/WP2015_DM_Full_Version.pdf. [Accessed: 2015] 